\title{
Effects of root phenotypic changes on the deep rooting of Populus euphratica seedlings under drought stresses
}

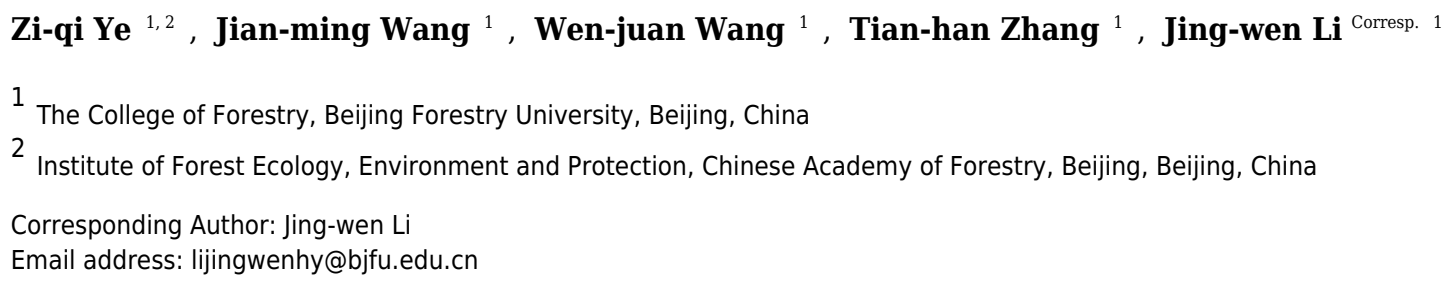

Background. Deep roots are critical for the survival of Populus euphratica seedlings on the floodplains of arid regions where they easily suffer drought stress. Drought typically suppresses root growth, but $P$. euphratica seedlings can adjust phenotypically in terms of root-shoot allocation and root architecture and morphology, thus promoting deep rooting . However, the root phenotypic changes undertaken by $P$. euphratica seedlings as a deep rooting strategy under drought conditions remain unknown. Methods. We quantified deep rooting capacity by the relative root depth (RRD), which represents the ratio of taproot length to plant biomass and is controlled by root mass fraction (RMF), taproot mass fraction (TRMF), and specific taproot length (STRL). We recorded phenotypic changes in one-year-old $P$. euphratica seedlings under control, moderate and severe drought stress treatments and assessed the effects of RMF, TRMF, and STRL on RRD. Results. Drought significantly decreased absolute root depth but substantially increased RRD via exerting positive effects on TRMF, RMF, and STRL. Under moderate drought, TRMF contributed $55 \%$, RMF $27 \%$ and STRL $18 \%$ to RRD variation. Under severe drought, the contribution of RMF to RRD variation increased to $37 \%$, which was similar to the $41 \%$ for TRMF. The contribution of STRL slightly increased to $22 \%$. Conclusion. These results suggest that the adjustments in root architecture and root-shoot allocation were predominantly responsible for deep rooting in $P$. euphratica seedlings under drought conditions, while morphological changes played a minor role. Moreover, $P$. euphratica seedlings rely mostly on adjusting their root architecture to maintain root depth under moderate drought conditions, whereas root-shoot allocation responds more strongly under severe drought conditions, to the point where it plays a role as important as root architecture does on deep rooting. 
1 Effects of root phenotypic changes on the deep

2 rooting of Populus euphratica seedlings under

3 drought stresses

4

5 Zi-qi Ye ${ }^{12}$, Jian-ming Wang1, Wen-juan Wang ${ }^{1}$, Tian-han Zhang ${ }^{1}$, Jing-wen Li $^{1 *}$

6

71 The College of Forestry, Beijing Forestry University, No. 35 Qinghua East Road, Haidian

8 District, Beijing 100083, China.

92 Institute of Forest Ecology, Environment and Protection, Chinese Academy of Forestry, No.2

10 Dongxiaofu, Xiangshan Road, Haidian District, Beijing 100091, China

11 *Corresponding Author: Jing-wen Li

12 Email address: lijingwenhy@bjfu.edu.cn 
14 ABSTRACT

Background. Deep roots are critical for the survival of Populus euphratica seedlings on the floodplains of arid regions where they easily suffer drought stress. Drought typically suppresses root growth, but $P$. euphratica seedlings can adjust phenotypically in terms of root-shoot allocation and root architecture and morphology, thus promoting deep rooting. However, the root phenotypic changes undertaken by $P$. euphratica seedlings as a deep rooting strategy under drought conditions remain unknown.

Methods. We quantified deep rooting capacity by the relative root depth (RRD), which represents the ratio of taproot length to plant biomass and is controlled by root mass fraction (RMF), taproot mass fraction (TRMF), and specific taproot length (STRL). We recorded phenotypic changes in one-year-old P. euphratica seedlings under control, moderate and severe drought stress treatments and assessed the effects of RMF, TRMF, and STRL on RRD.

Results. Drought significantly decreased absolute root depth but substantially increased RRD via exerting positive effects on TRMF, RMF, and STRL. Under moderate drought, TRMF contributed $55 \%$, RMF $27 \%$ and STRL $18 \%$ to RRD variation. Under severe drought, the contribution of RMF to RRD variation increased to $37 \%$, which was similar to the $41 \%$ for TRMF. The contribution of STRL slightly increased to $22 \%$.

Conclusion. These results suggest that the adjustments in root architecture and root-shoot allocation were predominantly responsible for deep rooting in P. euphratica seedlings under drought conditions, while morphological changes played a minor role. Moreover, $P$. euphratica seedlings rely mostly on adjusting their root architecture to maintain root depth under moderate drought conditions, whereas root-shoot allocation responds more strongly under severe drought conditions, to the point where it plays a role as important as root architecture does on deep rooting. 
 \\ INTRODUCTION}

The root system is the main plant organ acquiring below-ground resources. To adapt to the inherent heterogeneity of soil resources, plants can adjust root phenotype on different integrated levels (Chapin, 1991; Nicotra et al., 2010; Poorter et al., 2012): they can change their relative investment of biomass in shoots and roots on an individual-level, they can adjust root system architecture on an organ-level, or alter root morphology on a module-level (Fig. 1). Most likely, plants adjust their roots on all three levels. However, different environmental stresses may result in different degrees of root phenotypic adjustments, resulting in the different magnitude in functional contributions for plants under environmental stress. For instance, Freschet, Swart \& Cornelissen (2015) found that root mass fraction (RMF; the proportion of total plant mass allocated to roots) responded more strongly than specific root length (SRL; root length for a given unit of plant mass) to nutrient deficiency, thus suggesting that with nutrient stress, the increased allocation to roots seems more important than the root morphological change for the plant to achieve an increase in root length. Nevertheless, root architectural change is a basic way to improve fine-root function efficacy (Lynch, 1995; McCormack et al., 2017). Increasing the density and length of the distal roots can increase root absorption area (Kong et al., 2014). Additionally, different root patterns can influence plant uptake efficiency in heterogeneous resource environments (Lynch, 2005) and can affect the ability of root systems to capture relatively immobile versus mobile soil resources (Fitter, 1987). However, few studies have focused on the relative functional importance of the different phenotypic changes in stressed plants, especially the relative role of root architectural changes (Weemstra et al., 2016; Kramer-walter \& Laughlin, 2017; Freschet et al., 2018).

Populus euphratica Oliv. (Salicaceae) is a dioecious riparian tree species found discontinuously within the continental-arid climate region of Central Asia (Browicz, 1977; Wang, 1996), which forms monospecific stands along continental rivers. This poplar is an obligate phreatophyte with a root system that continuously contacts the groundwater or the soil watersaturated zone (Zhu et al., 2009), meaning that its growth and survival depends highly on locating and acquiring groundwater (Gries et al., 2003). However, its seedlings cannot reach groundwater 
65

66

67

during the early stages, meaning that under the harsh environments in arid regions, $P$. euphratica can only propagate generatively in the freshly deposited floodplain soils from May to August (Cao et al., 2012). Even so, the optimal soil conditions in such floodplains for seedling germination and growth only exist for a short time, as the surface soil post-flood rapidly becomes increasingly dry and salty due to evaporation. The rapid onset of winter also shortens the growth period for the seedlings. As a result, $P$. euphratica seedlings must establish a deep root system during the early stage, as only seedlings with deep roots can secure water uptake during the dry period and survive the following year (Zerbe \& Thevs, 2011). According to Thevs et al. (2008), Wiehle et al. (2009), and our previous field investigations, $P$. euphratica seedlings established in floodplains possess deep root systems very asymmetrical in size to the shoots. Therefore, deep rooting is considered a key process for survival and establishment of early $P$. euphratica seedlings in an inconsistent riparian environment (Hukin et al., 2005; Wang et al., 2015).

Populus euphratica seedlings are easily subjected to drought stress in semi-arid regions, (Thevs et al., 2008; Stella et al., 2010), which decreases biomass accumulation and limits root development into the deep soil. Accordingly, they take some phenotypic adjustments in order to deal with drought stress, such as increased root biomass allocation (Wang et al., 2015), root architecture adjustment and root morphology regulation (i.e., increased SRL; Lü et al., 2015). Each of these changes was believed to cause increased seedling root depth. However, as previously outlined, different levels of phenotypic changes may have different functional contributions, and thus the knowledge is still incipient regarding the exact effects of root phenotypic changes on the root depth of $P$. euphratica seedlings under drought stress. Further research on this issue would aid in our understanding of the drought adaptive strategy of $P$. euphratica and other similar deeprooted plants in the arid regions.

To understand the changes to plant root depth in response to environmental conditions, it is important to distinguishing between absolute and relative plant dimensions because water deficit may strongly influences the overall plant size in a negative manner (Fig. 1), which often obscures the underlying deep-rooting process (Schenk \& Jackson, 2002). Therefore, we adopted the 
92 absolute root depth to total plant biomass ratio to quantify relative root depth (RRD), i.e., deep93 rooting capacity, which follows the method of Ryser \& Lambers (1995) who used root length per 94 total plant biomass to express the relative length of fine roots, i.e., root uptake capacity. Here, we 95 define deep-rooting capacity as the capacity of the plant use all available resources to achieve an 96 increase in root depth via all possible ways. As so, deep-rooting capacity is regarded as an overall 97 capacity that could be depicted by several facets of drought responses (this definition is similar to 98 that of root nutrient acquisition capacity used by Freschet et al. (2018)). Thus, RRD 99 mathematically follows from the increases in RMF and/or the proportion of root system mass invested in taproot (i.e., taproot mass fraction (TRMF)) and/or the taproot length achieved per unit taproot mass (i.e., specific taproot length (STRL)) (see Eq. 1).

102 The present study aimed to answer the following questions: (1) How do P. euphratica 103 seedling roots change phenotypically on the individual-, organ- and modular- levels under drought 104 stress? (2) Which level of root phenotypic adjustment (root-shoot allocation, root architecture, or 105 morphology) plays a leading role in facilitating the deep rooting of the drought-stressed seedlings?

106 and (3) Does the relative contributions of these different root phenotypic adjustments on deep 107 rooting vary with drought intensity? 
109

110

111

112

113

114

115

116

117

118

119

120

121

122

123

124

125

126

127

128

129

130

131

132

133

134

135

\section{MATERIALS \& METHODS}

\section{Experimental method}

Nursery phase

This study was conducted at the State Forest Farm located in Ejin Banner, Inner Mongolia, China. All seeds were randomly collected from a mature natural forest dominated by $P$. euphratica $\left(41^{\circ} 57\right.$ 51.3" N, $101^{\circ} 05$ 06.0" E) along the Ejin River. Planted pots were $20 \mathrm{~L}$ in volume, $40 \mathrm{~cm}$ in depth, and filled with $16 \mathrm{~kg}$ (dry weight) of substrate - a 4/6 (v/v) mixture of peat and sand. A slowrelease fertilizer ( $4 \mathrm{~g} \mathrm{~L}^{-1}$ Osmocote 16:9:12 NPK and trace elements, product code: 8840 ) was premixed within the substrate. From May to June 2016, P. euphratica seeds were sown and germinated in 90 plastic pots placed in a greenhouse. After a month of growth with normal management, three seedlings per pot, averaging $2.0 \pm 0.5 \mathrm{~cm}$ in height and bearing four to six leaves, were selected and transferred to the open-air nursery. After two weeks of acclimation, only a single healthy seedling per pot, averaging $7.0 \pm 1.5 \mathrm{~cm}$ in height and $0.9 \pm 0.2 \mathrm{~mm}$ in ground diameter, was kept. This nursery phase took about 50 days.

\section{Experimental treatments}

This experiment was conducted over a period of 60 days from July to September 2016, during which the average of daily minimum and maximum temperatures were $21.7{ }^{\circ} \mathrm{C}$ and $34.3{ }^{\circ} \mathrm{C}$ respectively. The daily maximum temperature ranged from $25^{\circ} \mathrm{C}$ to $44{ }^{\circ} \mathrm{C}$. The experiment was conducted in a completely randomized design, including three water treatments: $70-80 \%$ of field capacity [(optimal water content $(\mathrm{OW})], 50-60 \%$ of field capacity [moderate drought stress (MD)], and $30-40 \%$ of field capacity [(severe drought stress (SD)]. Each treatment was replicated 30 times, and each replication consisted of s a seedling planted in an independent pot.

The seedlings were randomly assigned to one of the three treatments to avoid the variance in individual growth. Pot body was completely hidden into ground to avoid pot warming and just exposed surface soil to the arid climate, by which the soil in pot could have the relative real underground temperature and moisture in vertical gradient. Because the evapotranspiration rate in Ejin is high during summer days, soil water content was supplemented every day using the weight 
136

137

138

139

140

141

142

143

144

145

146

147

148

149

150

151

152

153

154

155

156

157

158

159

160

161

162

\section{1}

method to keep it at a certain range. After water supplementation, the pots were rearranged randomly to neutralize the influence of potential environmental heterogeneity. Plastic film was used to cover the nursery to avoid rainfall. Owing to the death of five seedlings subject to the SD treatment, and to the destruction of two seedlings from OW treatment and two seedlings from MD treatment during destructive sampling and root measurements, only 81 seedlings were successfully measured and accessed to analyses.

\section{Growth measurements and destructive sampling}

Intact root systems were cleaned of soil with a gentle water jet while a sieve was used to collect any root fragments detached from the system during this process. The cleaned root systems were then floated on water in a transparent tray and imaged using an Epson Expression Perfection V850 Pro Scanner with 800 dpi resolution (Fig. 2). Adobe Photoshop CS6 software was used to reduce image noise and black margins. The image analysis software (Win-RhIZO 2013a Pro Instruments Inc., Québec, Canada) was used to analyze images and to estimate the length of total, lateral, and distal roots, the average diameter of the total roots, the number of lateral roots, as well as the external path length $\left(\mathrm{p}_{\mathrm{e}}\right)$, magnitude $(\mu)$, and altitude $(a)$ (Table 1). The taproot was then detached from the root system with scissors, and its length and dry mass were determined. Lateral roots were defined as the root segments connected to the taproot with a root order $>3$, so as to guarantee that such roots perform conducting and foraging functions. Three intact lateral root branch segments with over three levels of root order were selected randomly and scanned to estimate the average length and diameter of the distal roots. Using a scalpel, all distal fine roots were dissected and was determined with its dry mass. If it was impossible to meet these criteria, the whole root system was measured. The dry weights of the taproot, sampled distal roots, and the other root parts were obtained by air drying plant matter in an oven at $72{ }^{\circ} \mathrm{C}$ for $60 \mathrm{~h}$. Total root biomass, specific root length, biomass-related variables, and two topological indices were calculated using these dry weight values (Table 1).

\section{Root phenotypic adjustments and deep-rooting capacity analysis}


163

164

165

166

167

168

169

170

171

172

173

174

175

176

177

178

179

180

181

182

183

184

185

186

187

188

189

As in many other studies, root-shoot allocation was quantified as the fraction of plant biomass invested in the roots (RMF; see Table 1 for definition), and taproot morphological change could be expressed as specific taproot length (STRL; see Table 1 for definition). These two aspects of root phenotypic change both have independent effects in the adjustment of root length (i.e., root depth in this study).

As it is difficult to fully measure root architecture, previous studies commonly used topology to describe the altered branching patterns indicative of a facet of the root architectural change (Fitter, 1987; Harper, Jones \& Sackville, 1991; Lynch, 1995). Here, we not only used the topological index (Fitter, 1987; Glimskär, 2000) and the dichotomous branching index (Šmilauerová \& Šmilauer, 2002), both commonly applied to characterize root topology (i.e., TI and DBI, respectively; see Table 1 for definitions), but also used the taproot mass fraction (TRMF; see Table 1 for definition) to characterize root architectural change.

It is logical to characterize root architecture as the biomass proportion of a certain functional root module in relation to the whole root system (e.g. TRMF) because the root branching pattern just refers to the coordinated growing relation among different functional root modules, and this relation could be represented with biomass proportion as a mass proxy. In particular, an extreme herringbone-like branching pattern has been found to be primarily confined to the main axis (Fitter et al., 1991) - that is, possessing the largest proportion of taproot biomass. Therefore, considering taproot as a key root module functioning in deep rooting, in this study TRMF was specially used to trace the facet of root architectural change that contribute to deep rooting. In addition, the correlation between TRMF and the commonly used TI and DBI has been examined to determine the availability of TRMF to represent root architecture $\left(\mathrm{R}^{2}=0.643\right.$ and 0.698 respectively, both $\mathrm{P}<$ 0.001); Fig. S1), and the results indicated that TRMF could be feasibly used in this study.

Populus euphratica has an obvious taproot that determines root system depth, and thus absolute root depth can be reflected by taproot length. Accordingly, relative root depth (RRD; see Table 1) was calculated as the absolute taproot length to taproot biomass ratio. Finally, RRD can be factored into RMF, TRMF, and STRL, as follows: 


$$
\mathrm{RRD}=\mathrm{RMF} \times \mathrm{TRMF} \times \mathrm{STRL}
$$

192

193

194

195

196

197

198

199

200

201

202

203

204

205

206

207

208

209

210

211

212

213

214

215

216

\section{Data analyses}

Differences observed in biomass allocation as well as in root architecture and morphology among the three drought treatments were tested using one-way analysis of variance (ANOVA, Welch's F test). After that, variations of statistical significance were further subjected to post hoc pairwise analysis by applying $t$-tests with Bonferroni corrections, or Games-Howell tests if the homogeneity of variances was not assumed, considering $P<0.05$ as significant. The dependence between TRMF and TI or TRMF and DBI was determined by Pearson's correlation analysis. Statistical analyses were performed in SPSS (version 19, SPSS Inc., Chicago, IL, USA).

We calculated the relative contributions of the variance in RMF, TRMF, and STRL to RRD, referencing the variance partitioning method of Rees et al. (2010) and Freschet et al. (2015). Given that $\mathrm{RRD}=\mathrm{RMF} \times \mathrm{TRMF} \times \mathrm{STRL}$, our calculation can be expressed as:

$$
\mathrm{rrd}=\mathrm{rmf}+\operatorname{trmf}+\mathrm{strl}
$$

where the lowercase acronyms indicate $\log _{\mathrm{e}}$-transformed variables (e.g., $\operatorname{rrd}=\ln (\mathrm{RRD})$ ). Thus, the variance decomposition of rrd, for instance, can be expressed as follows:

$\operatorname{Var}(\mathrm{rrd})=\operatorname{Var}(\mathrm{rmf})+\operatorname{Cov}(\mathrm{rmf}, \operatorname{trmf})+\operatorname{Cov}(\mathrm{rmf}, \mathrm{strl})+\operatorname{Var}(\operatorname{trmf})+\operatorname{Cov}(\mathrm{rmf}, \operatorname{trmf})+\operatorname{Cov}$ $($ trmf, strl $)+\operatorname{Var}($ strl $)+\operatorname{Cov}($ rmf, strl $)+\operatorname{Cov}(\operatorname{trmf}$, strl $)$.

Following Eq. 3, as a sample, the contribution of variation in trmf to the variation in rrd can be written as:

$$
\operatorname{Cont}(\operatorname{trmf})=[\operatorname{Var}(\operatorname{trmf})+\operatorname{Cov}(\mathrm{rmf}, \operatorname{trmf})+\operatorname{Cov}(\operatorname{trmf}, \operatorname{strl})] / \operatorname{Var}(\mathrm{rrd}),
$$

where Var is the variance and Cov is the covariance. This variance partitioning was only performed when substantial variation (i.e., $\geq 15 \%$ ) in rrd was observed across treatments, so as to avoid meaningless results. 
217

218

219

220

221

222

223

224

225

226

227

228

229

230

231

232

233

234

235

236

237

238

239

240

241

242

243

\section{Drought-induced phenotypic changes in biomass, root morphology, and root architecture}

Drought stress inhibited $P$. euphratica seedlings' growth in both biomass and root morphology (Table 2). Drought conditions caused a dramatic decrease in the biomass of different plant parts, total root length, the average length of lateral roots and distal roots and taproot length. However, when examining responses to differing drought intensities, taproot length and taproot biomass did not display a consistent declining trend with increasing drought intensity, and there was no difference in taproot length and taproot biomass between MD and SD treatments (Table 2). Moreover, the diameter of different root classifications had different responses to drought (Table 2). Root diameter (calculated with total roots) did not change significantly under drought conditions, but distal root diameter increased and lateral root diameter decreased significantly (Table 2). Taproot diameter decreased with drought, but not significantly. Furthermore, while the SRL (calculated with total roots) did not change by drought, the SRL of the distal roots (i.e., SDRL) - the root components more actively involved in water uptake - showed a significant decrease in SD in relation to OW (Table 2).

Populus euphratica seedlings showed a high plasticity in root branching patterns under different drought stresses. DBI and TI measures the degree to which a root is perfectly herringbone (DBI or TI equal to 1 ) or dichotomous branching (DBI equal to 0 , or TI close to 0.5 ). Values of DBI and TI differed significantly among the three drought treatments, but both of them in MD didn't differ from in OW or in SD. (Table 2). The ranges of value presented by the total samples were 0.650 to 0.844 for $\mathrm{TI}$ and 0.032 to 0.392 for DBI. Lateral root branching density, a simple but direct trait reflecting root branching, showed a markedly decreased trend from OW to SD treatments (Table 2).

\section{Different levels of root phenotypic variables related to deep rooting changed differently under drought}

Drought had a significant positive effect on RRD, but this increase was not proportional to the differences in RRD between $\mathrm{SD}$ and $\mathrm{MD}$, it was almost three times greater than the difference in 
244

245

246

247

248

249

250

251

252

253

254

255

256

257

258

259

260

261

262

263

264

265

266

267

268

269

270

RRD between MD and OW (Table 3). Regarding the indices representing different levels of root phenotypic changes, RMF and TRMF increased markedly with increasing drought severity, while STRL did not significantly increase under drought conditions. In addition, the TRMF under SD was not significantly different from that under MD, but RMF markedly increased under SD in relation to that under MD (Table 3).

\section{Relative contributions of different root phenotypic changes to deep rooting}

These results indicated that drought stress had a positive effect on RRD mainly via significant positive effects on TRMF and RMF. Generally, TRMF and RMF contributed to over $75 \%$ of the variation in RRD, while STRL contributed to approximately only $20 \%$ (Fig. 3). Moreover, TRMF always had the largest relative contribution to the variation of RRD both under MD (55\%) and under SD (41\%) in relation to that under OW (Fig. 3). Furthermore, the relative contributions of RMF, TRMF, and STRL to RRD variation changed with drought intensity (Fig. 3). TRMF contributed $55 \%$ of RRD variation between $\mathrm{MD}$ and $\mathrm{OW}$, which was larger than the $27 \%$ contributed by RMF and $18 \%$ by STRL. However, under severe drought stress, RMF contributed to $37 \%$ of the variation in RRD, nearly equal with $41 \%$ for TRMF. The contribution of STRL on RRD variation also increased slightly to $22 \%$. In addition, the variation of RRD from MD to SD treatments was even more attributable to RMF changes (41\%) than to TRMF changes (36\%) (Fig. 3).

\section{DISCUSSION}

Root adaptive responses to drought stress in terms of allocation, morphology, and architecture

One of the basic ways for plants to adapt to a shortage of below-ground resources is to maximize fine root area (e.g., decreased root diameter (RD) and increased SRL under drought stress) (Fitter, 1985; Cortina et al., 2008; Olmo, Lopez-Iglesias \& Villar, 2014). However, in the present study, the RD and SRL of whole roots exhibited no significant change, but the RD of distal roots 
271 increased and SDRL decreased under drought conditions (Table 2). Commonly, roots with a 272 smaller RD and higher SRL is advantageous under drought stress, as the smaller RD conveys 273 higher resistance to root embolism (Alameda \& Villar, 2012) through the smaller xylem vessel 274 diameter (Fitter, 1987), and a higher SRL probably is meant to commit limited carbohydrate supply 275 for extensional growth (Trubat, Cortin \& Vilagrosa, 2006). The unusual results (increased RD of 276 distal root and decreased SDRL under drought) in this study were likely due to the smaller SRL, 277 which is positively correlated with root life span and respiration rate (McCormack et al., 2012), 278 allowing $P$. euphratica seedlings to save considerable energy in dry soil through a low root

279

280

281

282

283

284

285

286

287

288

289

290

291

292

293

294

295

296

297 turnover rate in distal roots. Moreover, thicker fine roots would be able to penetrate into the more compacted soils imposed by soil drying (Bengough et al., 2005). In addition, the thicker distal roots of $P$. euphratica seedlings show higher drought resistance to preserve their vitality in the topsoil of arid-region floodplains where soil water availability is widely fluctuating with the regime of flood and dry seasons (Leon et al., 2011).

Plants mostly elongate root internode lengths to adapt to drought environments (Nicotra \& Westoby, 2002) as this also extends the volume of root exploring (Fitter \& Stickland, 1992). However, in our results, average root length did not significantly change and lateral root length clearly decreased under drought stress (Table 2). Ecologically, floodplain soil possesses a high infiltration rate, which is due to sandy soil layer (several meters in depth) deposited under the 10$50 \mathrm{~cm}$ deep surface clay soil layer formed by floodwater sedimentation (Thevs et al., 2008). Thus, rooting downward into deep soil is more critical for drought-stressed $P$. euphratica seedlings than rooting in other directions and shortening most of their lateral roots can avoid inefficient investments in the horizontal exploration of soil zone (Padilla \& Pugnaire, 2007; Bauerle et al., 2008).

Root architecture plays a major role in determining root resource-uptake efficiency (Fitter, 1987; Lynch, 2005). This multidimensional root feature is generally described by measuring root topology (Harper et al., 1991) or branching density/intensity (Kong et al., 2014). In the present study, the lateral root branching density was reduced under drought conditions (Table 2). From a 
298 functional point of view, the sparse lateral root branching of $P$. euphratica seedlings seems to

299

300

301

302

303

304

305

306

307

308

309

310

311

312

313

314

315

316

317

318

319

320

321

322

323

324

conserve the high metabolic cost of root construction and maintenance, which can commonly exceed $50 \%$ of daily photosynthesis (Lambers, Atkin \& Millenaar, 2002). Besides, the sparse lateral root branching may reduce the competition for water among the roots of an individual plant (Fitter et al., 1991; Taub \& Goldberg, 1996), which effectively increases the uptake efficiency per unit of lateral root length (Postma, Dathe \& Lynch, 2014).

Our results indicated that $P$. euphratica seedlings tended to create a herringbone-like branching pattern under drought conditions (Fig. 2), as revealed by the increased TI and DBI values under increased drought treatments (Table 2). This finding is in line with most model-based and empirical studies conducted on plants under drought conditions (Fitter, 1991; Taub \& Goldberg, 1996). Herringbone-like root systems possess higher exploration efficiency (Ho et al., 2005; Paula \& Pausas, 2011), thereby allowing for P. euphratica seedlings to reach water-rich deep soils quickly. Additionally, it should be noticed that in our experiment there is a vertical soil moisture gradient in the plant pots. Other studies performed with more actual ground water conditions and different soil texture layers would be an alternative strategy to determine and confirm deep-rooting of $P$. euphratica seedlings.

\section{Changes in absolute and relative root depth under drought stress}

The four-month-old $P$. euphratica seedlings grown in our experiment ultimately presented total biomasses ranging from about $0.2-0.5 \mathrm{~g}$ (Table 2), and, surprisingly, they developed taproots with approximately 26 to $35 \mathrm{~cm}$ long (Table 2). This indicates that, despite their low biomass accumulation rate, $P$. euphratica seedlings have a great capability to root deeply at their early stages. The miniscule biomass accumulation by the first-year seedlings might be due to their extremely small and light seeds $(0.1-0.2 \mathrm{~g}$ per thousand seeds). A similar ontogeny was also found in other studies concerning first-year riparian seedlings. An experiment under drought conditions conducted by Wang et al. (2015) showed that $P$. euphratica seedlings sown in April had about $1 \mathrm{~g}$ dry mass and over $22 \mathrm{~cm}$ taproot length by the end of July. Likewise, a study of riparian tree seedlings (family Salicaceae) conducted by Stella et al. (2010) demonstrated that three-month-old 
325

326

327

328

329

330

331

332

333

334

335

336

337

338

339

340

341

342

343

344

345

346

347

348

349

350

351

cottonwood seedlings ( $P$. fremontii) had $0.3 \mathrm{~g}$ dry weight with roots over $20 \mathrm{~cm}$ in depth, and that three-month-old Salix exigua and S. gooddingii seedlings developed root depths exceeding $25 \mathrm{~cm}$ and $40 \mathrm{~cm}$, respectively, despite exhibiting dry weights of only $0.22 \mathrm{~g}$ and $0.4 \mathrm{~g}$, respectively. Clearly, the tiny but deep-rooting seedling phenotype seems common in riparian tree species growing in arid regions.

Changes in plant root depth under drought stress are controlled by two processes (Fig. 1) (Sultan, 2000). On the one hand, drought stress weakens photosynthesis, dwindles the accumulated biomass and body size, and thereby leads to a shortening of the root depth. On the other hand, the root depth is influenced by different drought-induced root phenotypic responses. In this study, the absolute root depth of $P$. euphratica seedlings decreased significantly (Table 2) while the RRD increased significantly under drought conditions (Table 3), indicating that the limitation in growth caused by drought had an overwhelming effect on root depth, but which was compensated by enhancing deep-rooting capacity of $P$. euphratica seedlings under drought.

\section{Relative contributions of root phenotypic changes to the increase of relative root depth}

Our results indicated that changes to root architecture and root-shoot allocation in P. euphratica seedlings dominated for achieving deep rooting under drought conditions, while the role of morphological changes was minor (Fig. 3). This supports the perspective of Freschet et al. (2015) that root-shoot allocation was more important than root morphological changes for plant adaptations to changing environmental conditions. Besides, STRL in this study did not significantly increase under drought stress (table 3 ) and maintained relatively slight contributions to deep rooting regardless of drought intensity (Fig. 3), although taproot stretching seems to be an efficient way to increase root depth. This imply that phenotypic changes in module-level (morphology) seems not much important for plants to respond to belowground resources, given that the role of SRL of fine roots (absorptive roots) are also marginal for plant phenotypic adaption to nutrient limitation (Kramer-walter \& Laughlin, 2017). The potential negative effects of increased STRL on taproot function may account for this result. Because SRL is determined 
352 negatively by the root diameter and root tissue mass density (Nicotra \& Westoby, 2002), increased 353 STRL means decreased taproot diameter or tissue density. This negatively affects taproot 354 conduction, anchorage, and penetration, which are all essential functions for seedlings that are 355 suffering with drought conditions.

356 The relative contributions of changes in root-shoot allocation and root architecture were 357 altered under different drought intensities (Fig. 3). Under MD, root architectural changes played a 358 decisive role (contribution over 50\%) for increasing RRD. However, under SD, the root-shoot allocation response was stronger than that under MD (Table 3), and its relative contribution to deep rooting became nearly as important as that of root architectural changes (Fig. 3). This is likely because increased root-shoot allocation would have decreased photosynthetic capacity and accumulation of photosynthates (Muller et al., 2011). Root architecture changes seems more carbon economical under drought conditions, by which plant would root deeply only at the cost of weakening exploration capacity to the horizontal and surface soil (Thevs et al., 2008). Moreover, the variation of RRD from SD to MD is about three times that of the variation from OW to MD (Table 3), which indicates that keeping deep root is more important when drought becomes severe. Therefore, adjustment in root architecture seems to be insufficient for P. euphratica seedlings to root deeply under severe drought conditions. From a functional view, the seedlings possibly cannot easily acquire the adequate amount of water to maintain metabolic processes with increased drought stress. Accordingly, the seedlings would rely more on allocating biomass to roots, which have an advantage in minimizing water loss of shoot transpiration and in enhancing deep rooting potential (Brunner et al., 2015). In addition, our study revealed a practical implication for breeding P. euphratica seedlings. To promote the survival of container seedlings transplanted in the field, it is a good idea to breed the seedlings under moderate drought stress before transplantation, in order to promote deeper and steeper root systems while minimally affecting their sizes.

It has been widely reported for many plants, including $P$. euphratica seedlings (Bogeat-Triboulot et al., 2007), that root-shoot allocation responds significantly only to severe environmental stresses (Poorter et al., 2012). A general explanation is that plants maintain their above-ground growth for 
379 as long as possible under moderate soil environmental stresses to keep aboveground 380 competitiveness (Padilla et al., 2009; Poorter et al., 2012), but how plants tackle moderate 381 belowground resources stress to maintain shoot growth is still unclear. Our results indicate that $P$. 382 euphratica seedlings are able to adapt to moderate drought stress mainly via phenotypic 383 adjustments within their root systems. Here, we could raise an assumption that before root-shoot 384 allocation strongly responds to severe drought (Poorter et al., 2012), change in root architecture 385 mainly shoulder the absent role of root-shoot allocation for drought-suffered plant. This hypothesis 386 is based on a premise that plant phenotypic changes at the organ-level are more carbon economical 387 than that at the individual-level, while the latter should be more water economical than the former 388 for drought adaptation. To confirm this hypothesis, more functionally-different species need to be 389 further studied.

CONCLUSIONS

392

393

(1) Populus euphratica seedlings showed a conservative resource-use strategy in response to drought stress, evidenced by thicker and shorter distal roots with lower SRL, sparser lateral root branching, and herringbone-like root architecture under drought.

(2) The absolute root depth of $P$. euphratica seedlings was strongly constrained by drought, but this negative effect was alleviated by changes in root-shoot allocation, root architecture, and taproot morphology, resulting in a significant increase in relative root depth.

(3) Root architectural changes and root-shoot allocation dominated in order to achieve deep rooting under drought conditions, while the role of taproot morphological changes was relatively minor. Interestingly, their relative contributions to deep rooting varied with drought intensity. Under moderate drought conditions, root architectural changes exerted a predominant effect on increased relative root depth, but under severe drought, root-shoot allocation and root architecture played equally important roles. 


\section{ACKNOWLEDGEMENTS}

405 We are profoundly thankful to Ejin Banner State Forest Farm for support to conduct this 406 experiment, and to our colleagues Liu W., Dong. F.Y. and Zhong Y.M. for their assistance in the 407 field and indoors. We also thank the public infrastructure laboratory in the College of Forestry of 408 Beijing Forestry University for their support of instruments.

409 
410

411

412

413

414

415

416

417

418

419

420

421

422

423

424

425

426

427

428

429

430

431

432

433

434

435

436

\section{REFERENCES}

Alameda D, Villar R. 2012. Linking root traits to plant physiology and growth in Fraxinus angustifolia, vahl. seedlings under soil compaction conditions. Environmental \& Experimental Botany 79:49-57 DOI 10.1016/j.envexpbot.2012.01.004.

Bauerle TL, Smart DR, Bauerle WL, Stockert C, Eissenstat DM. 2008. Root foraging in response to heterogeneous soil moisture in two grapevines that differ in potential growth rate. New Phytologist 179:857-866 DOI 10.1111/j.1469-8137.2008.02489.x.

Bengough AG, Bransby MF, Hans J, McKenna SJ, Roberts TJ, Valentine TA. 2005. Root responses to soil physical conditions: growth dynamics from field to cell. Journal of Experimental Botany 57:437-447 DOI 10.1093/jxb/erj003.

Bogeat-Triboulot MB, Brosche M, Renaut J, Jouve L, Le Thiec D, Fayyaz P, Vinocur B, Witters E, Laukens K, Teichmann T, Altman A, Hausman JF, Polle A, Kangasjärvi J, Dreyer E. 2007. Gradual soil water depletion results in reversible changes of gene expression, protein profiles, ecophysiology, and growth performance in Populus euphratica, a poplar growing in arid regions. Plant Physiology 143:876-892 DOI 10.1104/pp.106.088708.

Browicz K. 1977. Chorology of Populus euphratica Olivier. Arboretum Kornickie 22:5-27.

Brunner I, Herzog C, Dawes MA, Arend M, Sperisen C. 2015. How tree roots respond to drought. Frontiers in Plant Science 6:547 DOI 10.3389/fpls.2015.00547.

Cao D, Li J, Huang Z, Baskin CC, Baskin JM, Hao P, Zhou W, Li J. 2012. Reproductive characteristics of a Populus euphratica population and prospects for its restoration in China. Plos One 7(7): e39121 DOI 10.1371/journal.pone.0039121.

Chapin FS III. 1991. Integrated responses of plants to stress. BioScience 41: 29-36 DOI: $10.2307 / 1311538$

Cortina J, Green JJ, Baddeley JA, Watson CA. 2008. Root morphology and water transport of Pistacia lentiscus seedlings under contrasting water supply: a test of the pipe stem theory. Environmental \& Experimental Botany 62:343-350 DOI 10.1016/j.envexpbot.2007.10.007.

Fitter AH. 1985. Functional significance of root morphology and root system architecture. In: 
437

438

439

440

441

442

443

444

445

446

447

448

449

450

451

452

453

454

455

456

457

458

459

460

461

462

463

Fitter AH, Read DJ, Atkinson D, Usher MB, eds. Ecological Interactions in Soil. Oxford, UK: Blackwell Scientific Publications, 87-106.

Fitter AH. 1987. An architectural approach to the comparative ecology of plant root systems. New Phytologist 106:61-77 DOI 10.1111/j.1469-8137.1987.tb04683.x.

Fitter AH, Stickland TR, Harvey ML, Wilson GW. 1991. Architectural analysis of plant root systems 1. Architectural correlates of exploitation efficiency. New Phytologist 118:375-382. DOI 10.1111/j.1469-8137.1992.tb01110.x.

Fitter AH, Stickland TR. 1992. Fractal characterization of root system architecture. Functional Ecology 6:632-635 DOI 10.2307/2389956.

Freschet GT, Swart EM, Cornelissen JHC. 2015. Integrated plant phenotypic responses to contrasting above- and below-ground resources: key roles of specific leaf area and root mass fraction. New Phytologist 206(4):1247-1260 DOI 10.1111/nph.13352.

Freschet GT, Violle C, Bourget MY, Scherer-Lorenzen M, Fort F. 2018. Allocation, morphology, physiology, architecture: the multiple facets of plant above- and below-ground responses to resource stress. New Phytologist. 219:4 DOI 10.1111/nph.15225.

Glimskär A. 2000. Estimates of root system topology of five plant species grown at steady-state nutrition. Plant \& Soil 227:249-256 DOI 10.1023/a: 1026531200864.

Gries D, Zeng F, Foetzki A, Arndt SK, Bruelheide H, Thomas FM, Zhang X, Runge M. 2003. Growth and water relations of Tamarix ramosissima, and Populus euphratica, on Taklamakan desert dunes in relation to depth to a permanent water table. Plant, Cell \& Environment 26:725736 DOI 10.1046/j.1365-3040.2003.01009.x.

Harper J, Jones M, Sackville HN. 1991. The evolution of roots and the problems of analysing their behaviour. In: Atkinson D, ed. Plant Root Growth: An Ecological Perspective. Oxford, UK: Blackwell Scientific Publications, 3-22.

Ho MD, Rosas JC, Brown KM, Lynch JP. 2005. Root architectural tradeoffs for water and phosphorus acquisition. Functional Plant Biology 32:737-748 DOI 10.1071/FP05043.

Hukin D, Cochard H, Dreyer E, Thiec DL, Bogeat-Triboulot MB. 2005. Cavitation 
464

465

466

467

468

469

470

471

472

473

474

475

476

477

478

479

480

481

482

483

484

485

486

487

488

489

490

vulnerability in roots and shoots: Does Populus euphratica Oliv., a poplar from arid areas of Central Asia, differ from other poplar species? Journal of Experimental Botany 56(418):20032010 DOI 10.1093/jxb/eri198.

Kramer-walter KR, Laughlin DC. 2017. Root nutrient concentration and biomass allocation are more plastic than morphological traits in response to nutrient limitation. Plant \& Soil 416(12):1-12 DOI 10.1007/s11104-017-3234-9

Kong D, Ma C, Zhang Q, Li L, Chen X, Zeng H, Guo D. 2014. Leading dimensions in absorptive root trait variation across 96 subtropical forest species. New Phytologist 203:86372 DOI 10.1111/nph.12842.

Lambers H, Atkin O, Millenaar FF. 2002. Respiratory patterns in roots in relation to their functioning. In: Waisel Y, Eshel A, Kafkaki K. eds. Plant roots: the Hidden Half. New York, USA: Marcel Dekker, 521-552.

Leon MF, Squeo FA, Gutierrez JR, Holmgren M. 2011. Rapid root extension during water pulses enhances establishment of shrub seedlings in the Atacama Desert. Journal of Vegetation Science 22(1):120-129 DOI 10.1111/j.1654-1103.2010.01224.x.

Lü S, Zhang X, Zhang N, Xia Y, Jing L, Li J. 2015. Response of root growth and architecture of Populus euphratica seedling to changes of soil moisture. (in Chinese with English abstract) Acta Botanica Boreali-Occidentalia Sinica 35:1005-1012.

Lynch JP. 1995. Root architecture and plant productivity. Plant Physiology 109:7-13 DOI 10.1104/pp.109.1.7.

Lynch JP. 2005. Root architecture and nutrient acquisition. In: Bassirirad H, ed. Nutrient Acquisition by Plants: An Ecological Perspective. Berlin, Germany: Springer, 147-183.

Markesteijn L, Poorter L. 2009. Seedling root morphology and biomass allocation of 62 tropical tree species in relation to drought- and shade-tolerance. Journal of Ecology 97:311-325 DOI 10.1111/j.1365-2745.2008.01466.x.

Muller B, Pantin F, Génard M, Turc O, Freixes S, Piques M, Gibon Y. 2011. Water deficits uncouple growth from photosynthesis, increase $\mathrm{C}$ content, and modify the relationships 
491

492

493

494

495

496

497

498

499

500

501

502

503

504

505

506

507

508

509

510

511

512

513

514

515

516

517

between $\mathrm{C}$ and growth in sink organs. Journal of Experimental Botany 62:1715-1729 DOI $10.1093 / \mathrm{jxb} / \mathrm{erq} 438$.

McCormack ML, Adams TS, Smithwick EH, Eissenstat DM. 2012. Predicting fine root lifespan from plant functional traits in temperate trees. New Phytologist 195:823-831. DOI 10.1111/j.1469-8137.2012.04198.x.

McCormack ML, Guo D, Iversen CM, Chen WL, Eissenstat DM, Fernandez CW, Li L, Ma C, Ma Z, Poorter H, Reich PB, Zadworny M, Zanne A. 2017. Building a better foundation: improving root-trait measurements to understand and model plant and ecosystem processes. New Phytologist 215(1):27-37 DOI 10.1111/nph.14459.

Nicotra AB, Westoby M. 2002. Seedling root anatomy and morphology: An examination of ecological differentiation with rainfall using phylogenetically independent contrasts. Oecologia 130(1):136-145 DOI 10.1007/s004420100788.

Nicotra AB, Atkin OK, Bonser SP, Davidson AM, Finnegan EJ, Mathesius U, Poot P, Purugganan MD, Richards CL, Valladares F, van Kleunen M. 2010. Plant phenotypic plasticity in a changing climate. Trends in Plant Science 15: 684-692 DOI 10.1016/j.tplants.2010.09.008

Olmo M, Lopez-Iglesias B, Villar R. 2014. Drought changes the structure and elemental composition of very fine roots in seedlings of ten woody tree species, implications for a drier climate. Plant \& Soil 384:113-129 DOI 10.1007/s11104-014-2178-6.

Padilla FM, Pugnaire FI. 2007. Rooting depth and soil moisture control Mediterranean woody seedling survival during drought. Functional Ecology 21:489-495 DOI 10.1111/j.13652435.2007.01267.x.

Padilla FM, Miranda JD, Jorquera MJ, Pugnaire FI. 2009. Variability in amount and frequency of water supply affects roots but not growth of arid shrubs. Plant Ecology 204:261270 DOI 10.1007/s11258-009-9589-0.

Paula S, Pausas JG. 2011. Root traits explain different foraging strategies between resprouting life histories. Oecologia 165(2): 321-331 DOI 10.1007/s00442-010-1806-y. 
518

519

520

521

522

523

524

525

526

527

528

529

530

531

532

533

534

535

536

537

538

539

540

541

542

543

544

Poorter H, Niklas KJ, Reich PB, Oleksyn J, Poot P, Mommer L. 2012. Biomass allocation to leaves, stems and roots: Meta-analyses of interspecific variation and environmental control. New Phytologist 193:30-50 DOI 10.1111/j.1469-8137.2011.03952.x.

Postma JA, Dathe A, Lynch JP. 2014. The optimal lateral root branching density for maize depends on nitrogen and phosphorus availability. Plant Physiology 166(2):590-602 DOI 10.1104/pp.113.233916.

Rees M, Osborne CP, Woodward FI, Hulme SP, Turnbull LA, Taylor SH. 2010. Partitioning the components of relative growth rate: how important is plant size variation. American Naturalist 176(6):E152 DOI 10.1086/657037.

Ryser P, Lambers H. 1995. Root and leaf attributes accounting for the performance of fast- and slow-growing grasses at different nutrient supply. Plant \& Soil 170:251-265 DOI $10.1007 / \mathrm{BF} 00010478$.

Sultan SE. 2000. Phenotypic plasticity for plant development, function and life history. Trends in Plant Science 5(12):537-542 DOI 10.1016/S1360-1385(00)01797-0.

Schenk HJ, Jackson RB. 2002. Rooting depths, lateral root spreads and below-ground/above-ground allometries of plants in water-limited ecosystems. Journal of Ecology 90:480-494 DOI 10.1046/j.1365-2745.2002.00682.x.

Stella JC, Battles JJ, Mcbride JR, Orr BK. 2010. Riparian seedling mortality from simulated water table recession, and the design of sustainable flow regimes on regulated rivers. Restoration Ecology 18:284-294 DOI 10.1111/j.1526-100X.2010.00651.x.

Šmilauerová M, Šmilauer P. 2002. Morphological responses of plant roots to heterogeneity of soil resources. New Phytologist 154(3):703-715 DOI 10.1046/j.1469-8137.2002.00416.x.

Taub DR, Goldberg D. 1996. Root system topology of plants from habitats differing in soil resource availability. Functional Ecology 10:258-264 DOI 10.2307/2389851.

Thevs N, Zerbe S, Peper J, Succow M. 2008. Vegetation and vegetation dynamics in the Tarim River floodplain of continental-arid Xinjiang, NW China. Phytocoenologia 38(2):65-84 DOI 10.1127/0340-269X/2008/0038-0065. 
545 Trubat R, Cortina J, Vilagrosa A. 2006. Plant morphology and root hydraulics are altered by 546 nutrient deficiency in Pistacia lentiscus (L.). Trees 20:334-339 DOI 10.1007/s00468-005547 0045-z.

548

549

550

551

552

553

554

555

556

557

558

559

560

561

562

563

564

Wang L, Zhao C, Li J, Liu Z, Wang J. 2015. Root plasticity of Populus euphratica seedlings in response to different water table depths and contrasting sediment types. PloS One 10:e0118691 DOI 10.1371/journal.pone.0118691.

Wang S. 1996. The Status, conservation and recovery of global resources of Populus euphratica. (in Chinese). World Forestry Research 6:37-44 DOI 10.13348/j.cnki.sjlyyj. 1996.06.005.

Weemstra M, Mommer L, Visser EJW, Ruijven J, Kuyper TW, Mohren GMJ, Sterck FJ. 2016. Towards a multidimensional root trait framework: A tree root review. New Phytologist 211(4):1159-1169 DOI 10.1111/nph.14003.

Wiehle M, Eusemann P, Thevs N, Schnittler M. 2009. Root suckering patterns in Populus euphratica, (Euphrates poplar, Salicaceae). Trees 23(5):991-1001 DOI 10.1007/s00468-0090341-0.

Zerbe S, Thevs N. 2011. Restoring central Asian floodplain ecosystems as natural capital and cultural heritage in a continental desert environment. In: Hong SK, ed. Landscape Ecology in Asian Cultures. Ecological Research Monographs. Tokyo, Japan: Springer 277-297.

Zhu Y, Ren L, Skaggs TH, Lü H, Yu Z, Wu Y, Fang X. 2009. Simulation of Populus euphratica root uptake of groundwater in an arid woodland of the Ejina Basin, China. Hydrology Process 23:2460-2469 DOI 10.1002/hyp.7353. 


\section{Figure 1}

Schematic representation of partitioning the total drought effect into environmental limitation of growth and different levels of root phenotypic responses

(A.) A scheme to increasing a certain root length through three levels of root phenotypic changes respectively. To achieve an increase of certain root length, plant can phenotypically adjust at three levels respectively, but most commonly, plant roots adjust at all three levels when they respond to drought. (B.) Drought exerts considerable influence in metabolism, causing an overall limitation of growth. (C.) Real growth situation is a syndrome from environmental limitation and multiple facets of integrated phenotypic responses 


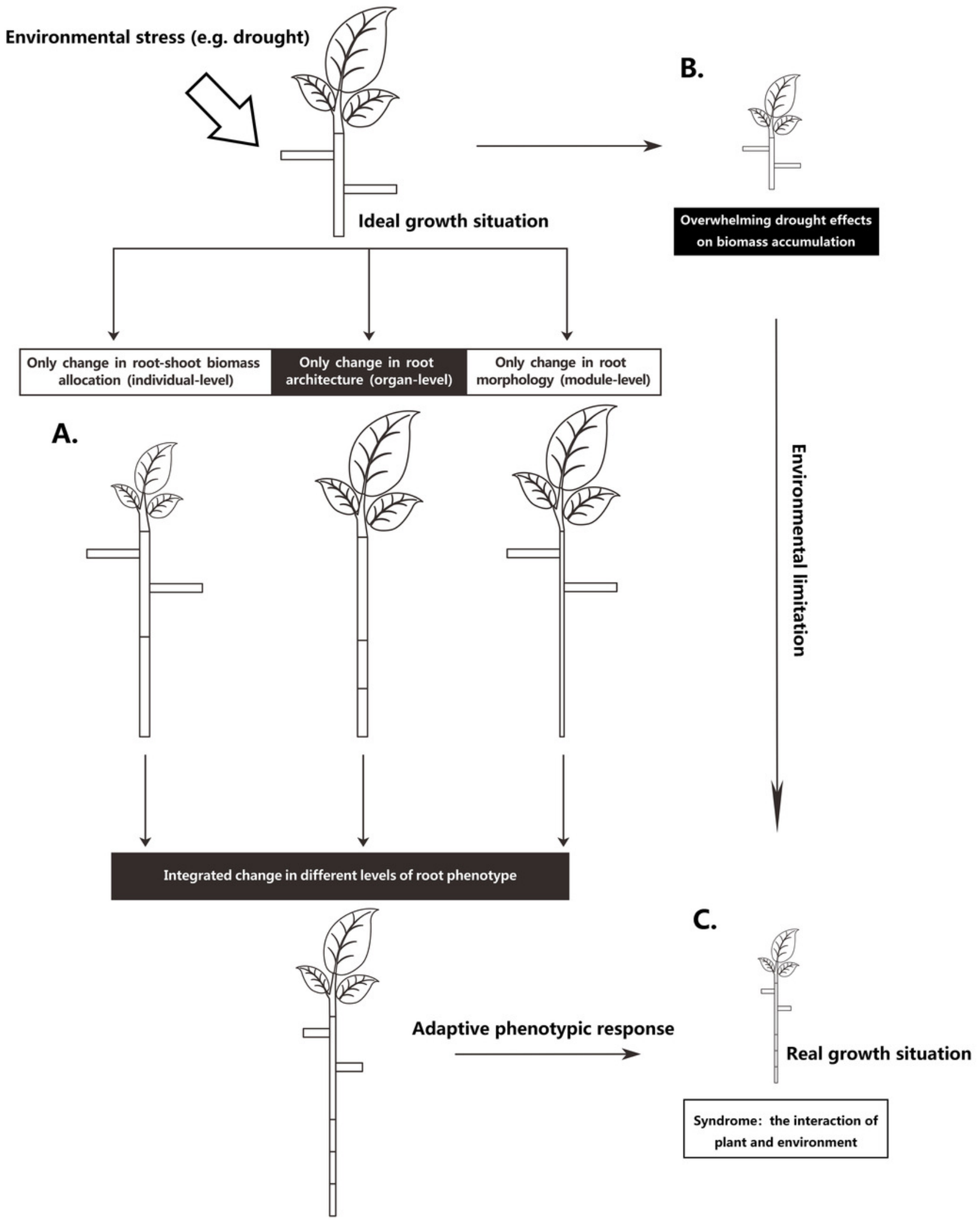




\section{Figure 2}

Representative scan images used in the study to illustrate changes in root system of $P$. euphratica seedlings with drought treatments

The representative root images of $P$. euphratica seedlings show the relatively denser branch, deeper root depth and more herringbone-like branching pattern of root with drought increasing. (A) \& (B) show the root images from the seedlings under $\mathrm{OW}$, in which their $\mathrm{Tl}=0.697, \mathrm{DB} I=0.056$, and $\mathrm{Tl}=0.650, \mathrm{DB}=0.032$, respectively. (C) \& (D) from the seedlings under $M D$, in which their $T I=0.702, D B I=0.074$, and $T I=0.702$, $\mathrm{DBI}=0.086$, respectively. $(\mathrm{E}) \&(\mathrm{~F})$ from the seedlings under $\mathrm{SD}$ in which their $\mathrm{TI}=0.754, \mathrm{DBI}=0.185$, and $\mathrm{Tl}=0.773, \mathrm{DBI}=0.258$, respectively. Note: OW: optimal water content; MD: moderate drought stress; SD: severe drought stress.DBI is the dichotomous branching index and TI is the topology index, and both of them are used to quantify root architectural changes (for detailed definition see table 1 ). A DBI of 0 is characteristic of a perfectly dichotomous branching structure and similarly, a TI close to 0.5 means a dichotomous-like branching structure. Contrastly, both a DBI of 1 and a TI of 1 represents a perfectly herringbone branching structure. 
A

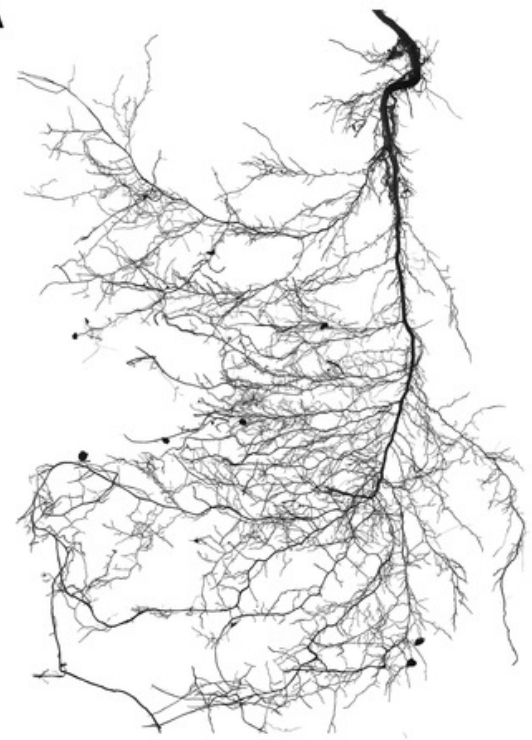

Optimal water content

B

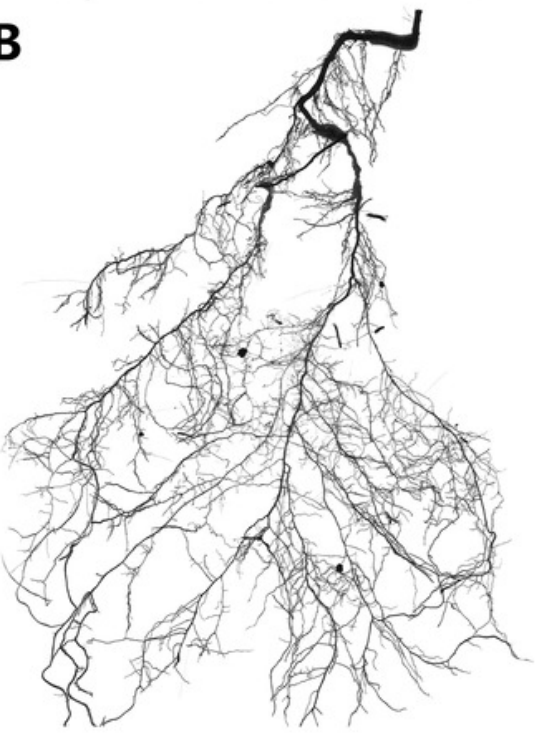

C

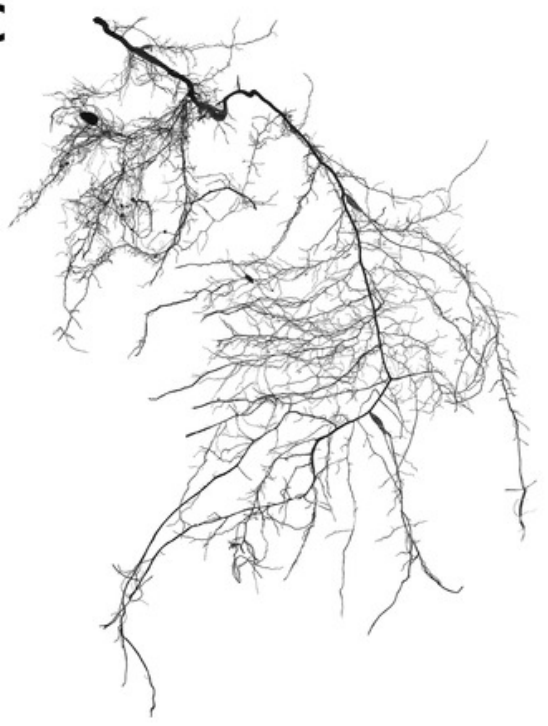

Moderate drought stress

D

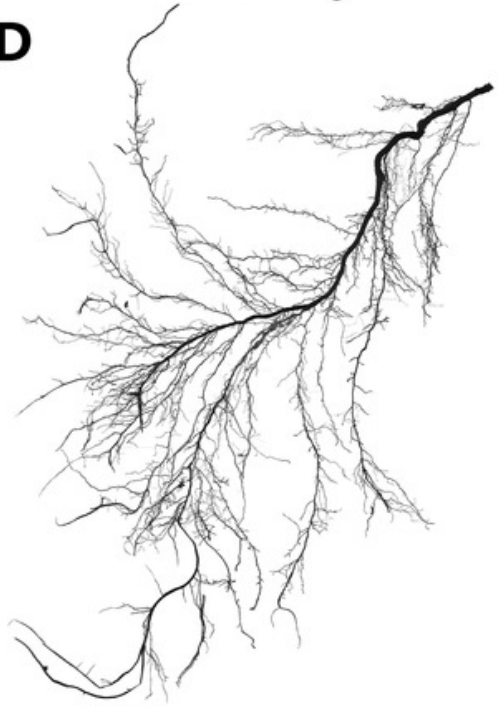

E

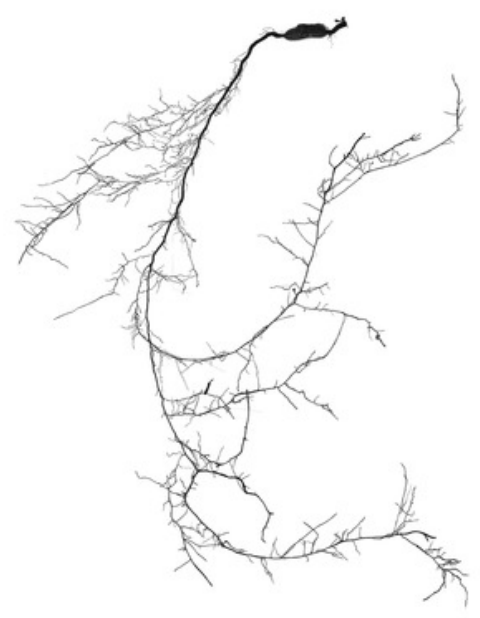

Severe drought stress

$\mathbf{F}$

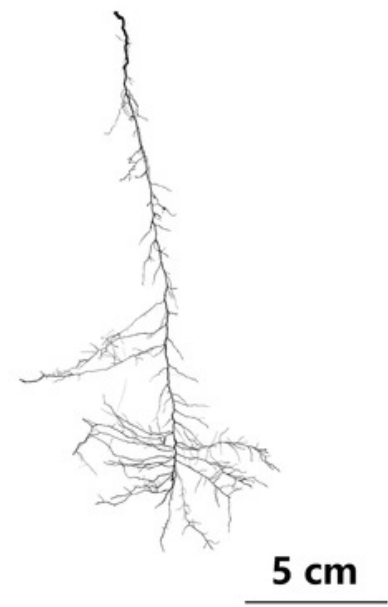




\section{Figure 3}

Relative contributions of root-shoot allocation (RMF, light grey bars), morphology (STRL, dark grey bars) and architecture (TRMF, black bars) variables to the variation in relative root depth (RRD).

From left to right, the first bar represents total contributions to the variation in RRD between OW and MD, the second bar represents that between OW and SD, and the third bar represents that between MD and SD. OW: optimal water content (control); MD: moderate drought stress; SD: severe drought stress.

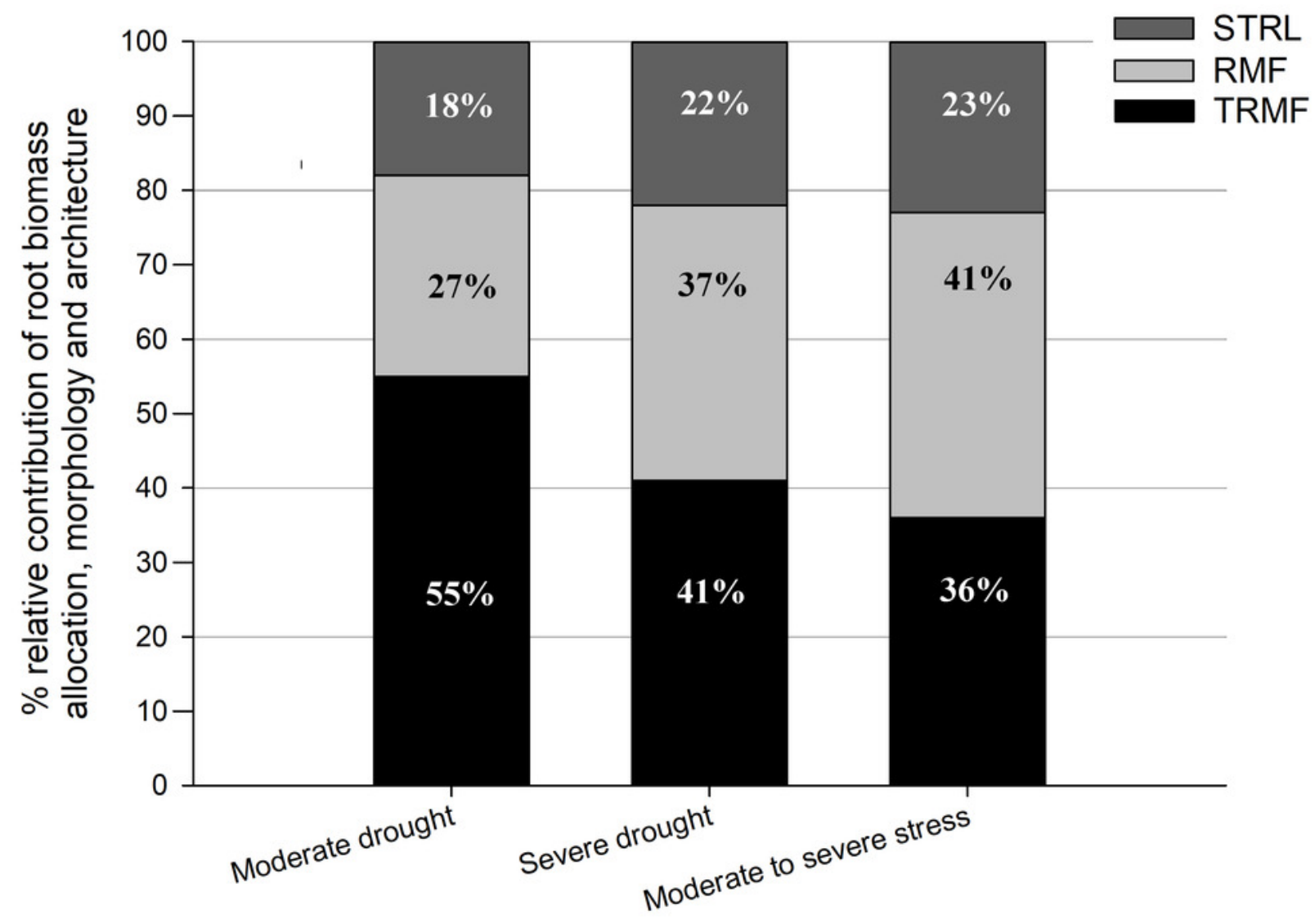




\section{Table $\mathbf{1}$ (on next page)}

Calculated root variables and its abbreviations, units, description and functional role 
1 Table 1 Calculated root variables and its abbreviations, units, description and functional role

Root variables

(Abbrev.)

Description

Functional role

units

\begin{tabular}{|c|c|c|}
\hline $\begin{array}{l}\text { Relative root depth } \\
(R R D) \\
\text { cm taproot }[\mathrm{g} \text { plant }]^{-1}\end{array}$ & Taproot length per total plant dry mass & Capacity for deep rooting. \\
\hline $\begin{array}{l}\text { Root mass fraction } \\
\qquad(R M F) \\
\mathrm{g} \operatorname{root}[\mathrm{g} \text { plant }]^{-1}\end{array}$ & $\begin{array}{l}\text { The proportion of total plant mass } \\
\text { allocated to roots }\end{array}$ & $\begin{array}{l}\text { Total plant resources allocated to } \\
\text { root functions (e.g. absorption, } \\
\text { transport, foraging, anchoring) } \\
\text { (Markesteijn \& Poorter, 2009) }\end{array}$ \\
\hline $\begin{array}{l}\text { Taproot mass fraction } \\
\qquad(T R M F) \\
\mathrm{g}_{\text {taproot }[\mathrm{g} \text { root }]^{-1}}\end{array}$ & $\begin{array}{l}\text { The proportion of total root mass } \\
\text { allocated to taproot }\end{array}$ & $\begin{array}{l}\text { Total root resources allocated to } \\
\text { the taproot functions.(e.g., } \\
\text { anchoring, foraging, transport) }\end{array}$ \\
\hline $\begin{array}{l}\text { Specific taproot length } \\
\qquad(S T R L) \\
\text { cm taproot }[\mathrm{g} \text { taproot }]^{-1}\end{array}$ & $\begin{array}{l}\text { Taproot length per amount of taproot } \\
\text { biomass invested }\end{array}$ & $\begin{array}{l}\text { The efficiency of taproot } \\
\text { resources used to deep rooting. }\end{array}$ \\
\hline $\begin{array}{l}\text { Lateral root branching } \\
\text { density }(L R B D) \\
\text { number lateral } \\
\text { root }[\mathrm{cm} \text { taproot }]^{-1}\end{array}$ & $\begin{array}{l}\text { Lateral roots branching number per } \\
\text { unit of taproot length }\end{array}$ & $\begin{array}{l}\text { Potential capacity of exploration } \\
\text { and exploitation to horizontal } \\
\text { soil resources }\end{array}$ \\
\hline Topology Index (TI) & $\begin{array}{l}\mathrm{TI}=\log _{10}(\mathrm{a}) / \log _{10}(\mu) \text {; altitude } \mathrm{a} \text { is } \\
\text { number of links in the longest path } \\
\text { from base to tips; magnitude } \mu \text { is } \\
\text { number of external links or the } \\
\text { number of root tips (Glimskär, 2000) }\end{array}$ & \multirow{2}{*}{$\begin{array}{l}\text { TI vary from } 1 \text { close to } 0.5 \text {, and } \\
\text { DBI vary between } 0 \text { and } 1 \text {, both } \\
\text { with large values indicative of a } \\
\text { more herringbone-like root } \\
\text { system that are thought to be } \\
\text { more efficient at intercepting } \\
\text { mobile resources, such as water, } \\
\text { by extensive soil exploration, } \\
\text { contrasted with dichotomous- } \\
\text { like systems that are better at } \\
\text { acquiring immobile resources, } \\
\text { such as phosphorus by intensive } \\
\text { soil exploration (Fitter, 1987) }\end{array}$} \\
\hline $\begin{array}{l}\text { Dichotomous } \\
\text { branching index }(D B I)\end{array}$ & $\begin{array}{l}\mathrm{DBI}=\left[\mathrm{p}_{\mathrm{e}}-\min \left(\mathrm{p}_{\mathrm{e}}\right)\right] /\left[\max \left(\mathrm{p}_{\mathrm{e}}\right)-\min \left(\mathrm{p}_{\mathrm{e}}\right)\right] \\
\mathrm{p}_{\mathrm{e}} \text { is the sum of the number of links in } \\
\text { all paths from each external link to the } \\
\text { base link; } \max \left(\mathrm{p}_{\mathrm{e}}\right) \text { and } \min \left(\mathrm{p}_{\mathrm{e}}\right) \\
\text { respectively is the theoretical external } \\
\text { path length for a system of given } \\
\text { magnitude that has a completely } \\
\text { herringbone and dichotomous } \\
\text { topology, for detailed calculation see } \\
\text { Šmilauerová \& Šmilauer }(2002)\end{array}$ & \\
\hline
\end{tabular}




\section{Table 2 (on next page)}

Mean values of biomass variables, root branching variables and root morphological variables of $P$. euphratica seedlings at 110 days under drought treatments

Notes: Differences in variables among treatments were tested using factorial analysis of variance (ANOVA). Values are means \pm standard error (OW: $n=25 ; M D: n=28 ; S D: n=28)$. In each row, means followed by different letters are significantly different $(P<0.05)$. OW, MD and SD refers to optimal water content (control), moderate drought stress and severe drought stress separately. SRL=Specific Root Length; SRDL=Specific Distal Root Length; $\mathrm{TI}=$ Topology Index; $\mathrm{DBI}=$ Dichotomous Branching Index. 
1 Table 2 Mean values of biomass variables, root morphological variables and root branching

2 variables of $P$. euphratica seedlings at 110 days under drought treatments

\begin{tabular}{|c|c|c|c|c|}
\hline & Variables & OW (control) & MD & SD \\
\hline \multirow{4}{*}{ Biomass } & Total plant biomass $(\mathrm{g})$ & $0.46 \pm 0.02^{\mathrm{a}}$ & $0.35 \pm 0.02^{b}$ & $0.22 \pm 0.02^{\mathrm{c}}$ \\
\hline & Above-ground biomass (g) & $0.30 \pm 0.02^{\mathrm{a}}$ & $0.23 \pm 0.02^{b}$ & $0.13 \pm 0.01^{\mathrm{c}}$ \\
\hline & Below-ground biomass (g) & $0.16 \pm 0.01 \mathrm{a}$ & $0.12 \pm 0.01^{b}$ & $0.09 \pm 0.01^{\mathrm{c}}$ \\
\hline & Taproot biomass (g) & $0.043 \pm 0.003^{\mathrm{a}}$ & $0.032 \pm 0.002^{b}$ & $0.030 \pm 0.002^{b}$ \\
\hline \multirow{11}{*}{ Morphology } & Total root length (cm) & $662 \pm 37^{a}$ & $516 \pm 44^{b}$ & $393 \pm 41^{c}$ \\
\hline & Average root length $(\mathrm{cm})$ & $0.376 \pm 0.048^{\mathrm{a}}$ & $0.367 \pm 0.038^{a}$ & $0.236 \pm 0.027 \mathrm{a}$ \\
\hline & Root diameter (mm) & $0.348 \pm 0.007 \mathrm{a}$ & $0.357 \pm 0.006^{\mathrm{a}}$ & $0.359 \pm 0.009^{\mathrm{a}}$ \\
\hline & $\mathrm{SRL}(\mathrm{cm} / \mathrm{g})$ & $4766 \pm 290^{\mathrm{a}}$ & $4846 \pm 357^{\mathrm{a}}$ & $5141 \pm 343^{a}$ \\
\hline & $\begin{array}{l}\text { Average distal root length } \\
(\mathrm{cm})\end{array}$ & $0.319 \pm 0.122^{\mathrm{a}}$ & $0.279 \pm 0.191^{b}$ & $0.156 \pm 0.057^{\mathrm{c}}$ \\
\hline & Distal root diameter $(\mathrm{mm})$ & $0.278 \pm 0.006^{\mathrm{c}}$ & $0.302 \pm 0.007^{b}$ & $0.337 \pm 0.007^{\mathrm{a}}$ \\
\hline & $\operatorname{SDRL}(\mathrm{cm} / \mathrm{g})$ & $10032 \pm 425^{a}$ & $9487 \pm 661^{a b}$ & $7843 \pm 361^{b}$ \\
\hline & $\begin{array}{l}\text { Average lateral root length } \\
(\mathrm{cm})\end{array}$ & $5.113 \pm 0.324^{\mathrm{a}}$ & $4.680 \pm 0.3333^{\mathrm{ab}}$ & $3.765 \pm 0.298^{c}$ \\
\hline & Lateral root diameter $(\mathrm{mm})$ & $0.881 \pm 0.035^{\mathrm{a}}$ & $0.757 \pm 0.034^{\mathrm{b}}$ & $0.653 \pm 0.029^{c}$ \\
\hline & Taproot length $(\mathrm{cm})$ & $35.3 \pm 1.1^{\mathrm{a}}$ & $27.3 \pm 0.8^{b}$ & $26.2 \pm 0.7^{b}$ \\
\hline & Taproot diameter (mm) & $1.60 \pm 0.091^{\mathrm{a}}$ & $1.48 \pm 0.093^{\mathrm{a}}$ & $1.35 \pm 0.082^{\mathrm{a}}$ \\
\hline \multirow{3}{*}{ Architecture } & $\mathrm{TI}$ & $0.713 \pm 0.007^{b}$ & $\begin{array}{l}0.731 \pm 0.008 \\
\mathrm{ab}\end{array}$ & $0.757 \pm 0.010^{\mathrm{a}}$ \\
\hline & DBI & $0.101 \pm 0.010^{b}$ & $\begin{array}{l}0.153 \pm 0.016 \\
\mathrm{ab}\end{array}$ & $0.216 \pm 0.020^{\mathrm{a}}$ \\
\hline & $\begin{array}{l}\text { Lateral root branching } \\
\text { density }(\mathrm{n} / \mathrm{cm})\end{array}$ & $1.21 \pm 0.09^{\mathrm{a}}$ & $1.03 \pm 0.05^{b}$ & $0.85 \pm 0.04^{\mathrm{c}}$ \\
\hline
\end{tabular}

3 Notes: Differences in variables among treatments were tested using factorial analysis of variance

4 (ANOVA). Values are means \pm standard error (OW: $n=25$; MD: $n=28 ; S D: n=28)$. In each row,

5 means followed by different letters are significantly different $(\mathrm{P}<0.05)$. OW, MD and SD refers to

6 optimal water content (control), moderate drought stress and severe drought stress separately.

$7 \quad \mathrm{SRL}=$ Specific Root Length; SRDL=Specific Distal Root Length; TI=Topology Index;

$8 \quad \mathrm{DBI}=$ Dichotomous Branching Index. 


\section{Table 3 (on next page)}

Representative indices of different root phenotypic changes and deep-rooting capacity of $P$. euphratica seedlings under drought treatments

Notes: Differences in Indices among treatments were tested using factorial analysis of variance (ANOVA). Values are means \pm standard error (OW: $n=25 ; M D: n=28 ; S D: n=28$ ). Within a row, means followed by different letters are significantly different $(P<0.05)$. OW, MD and SD refers to optimal water content (control), moderate drought stress and severe drought stress respectively. RMF=Root Mass Fraction; TRMF=Taproot Mass Fraction; STRL=Specific Taproot Length; RRD=Relative Root Depth. 
1 Table 3 Representative indices of different root phenotypic changes and deep-rooting

2 capacity of $\boldsymbol{P}$. euphratica seedlings under drought treatments

\begin{tabular}{llll}
\hline Indices & OW (control) & MD & SD \\
\hline RMF & $0.338 \pm 0.009^{\mathrm{b}}$ & $0.353 \pm 0.013^{\mathrm{b}}$ & $0.418 \pm 0.013^{\mathrm{a}}$ \\
TRMF & $0.304 \pm 0.018^{\mathrm{b}}$ & $0.333 \pm 0.026^{\mathrm{ab}}$ & $0.393 \pm 0.030^{\mathrm{a}}$ \\
$\mathrm{STRL}(\mathrm{cm} / \mathrm{g})$ & $889 \pm 37^{\mathrm{a}}$ & $919 \pm 45^{\mathrm{a}}$ & $1020 \pm 67^{\mathrm{a}}$ \\
RRD $(\mathrm{cm} / \mathrm{g})$ & $90.8 \pm 7.26^{\mathrm{b}}$ & $108.0 \pm 11.0^{\mathrm{ab}}$ & $166.0 \pm 15.9^{\mathrm{a}}$ \\
\hline
\end{tabular}

3 Notes: Differences in Indices among treatments were tested using factorial analysis of variance

4 (ANOVA). Values are means \pm standard error (OW: $n=25 ; M D: n=28 ; S D: n=28)$. Within a row,

5 means followed by different letters are significantly different $(\mathrm{P}<0.05)$. OW, MD and SD refer to

6 optimal water content (control), moderate drought stress and severe drought stress respectively.

$7 \quad \mathrm{RMF}=$ Root Mass Fraction; TRMF=Taproot Mass Fraction; STRL=Specific Taproot Length;

$8 \quad \mathrm{RRD}=$ Relative Root Depth. 